\title{
Determination of the discriminant score of intestinal microbiota as a biomarker of disease activity in patients with ulcerative colitis
}

Katsuyuki Fukuda* and Yoshiyuki Fujita

\begin{abstract}
Background: In recent years, the gut microbiota has been found to provide an important link to the development of inflammatory bowel diseases (IBD) like ulcerative colitis (UC). Accordingly, inter-individual variation in the gut microbial community may be linked to inter-individual variation in the risk of IBD or other diseases. Further, the Terminal Restriction Fragment Length Polymorphism (T-RFLP) is a molecular biology technique for profiling bacterial species in faecal samples. This study was to evaluate a biomarker based on intestinal microbiota.
\end{abstract}

Methods: The study subjects were 69 patients with UC together with 80 relatives as controls. Twenty-three patients had active UC (group I) and 46 had quiescent UC (group II). The later included 17 patients with mild inflammation in the large intestine (group Ila), 29 without inflammation (group Ilb). The patients' relatives were consanguineous (group III, $n=47$ ), and non-consanguineous (group IV, $n=33$ ). Faecal samples were obtained from all subjects for the investigation of intestinal microbiota by applying the T-RFLP method. The Discriminant analysis of operational-taxonomicunit (OTU) on T-RFLP fingerprints was performed. The Canonical Discriminant Function Coefficient (Df) for each OTU was calculated. The individual OTUs were multiplied by the Df value, and the sum was termed the Discriminant Score (Ds).

Results: The Ds decreased thus: group I > group Ila > group IIb > group III > group IV. Significant difference was calculated for group I vs group IV $(P<0.01)$, group I vs group IIb $(P<0.05)$, group I vs group III $(P<0.01)$, group IIa vs IV ( $P<0.01)$, group IIb vs group IV $(P<0.01)$, group III vs group IV $(P<0.01)$, indicating a strong association between gut microbial species and the development of UC.

Conclusions: In this study, the Ds related to UC, or otherwise absence of UC in the five groups. Potentially, Ds may become a clinically relevant biomarker of disease activity in UC. To our knowledge, this is the first application of the Ds to the study of microbiota in UC patients, consanguineous and non-consanguineous relatives.

Trial registration: Clinical trial No: UMIN 000004123.

Keywords: Intestinal microbiota, Ulcerative colitis, Terminal restriction fragment length polymorphism, Discriminant score, Operational-taxonomic-unit, Canonical discriminant function coefficient

\section{Background}

Inflammatory bowel disease (IBD) is a chronic relapsingremitting intestinal immune disorder that afflicts millions of individuals throughout the world with debilitating symptoms like diarrhea, rectal bleeding, and weight loss, which impair function and quality of life [1]. IBD has two major phenotypes, ulcerative colitis (UC) and Crohn's disease (CD). Although UC is primarily confined to the colon

\footnotetext{
* Correspondence: fukukats@luke.or.jp

Department of Gastroenterology, St Luke's International Hospital 9-1, Akashi Tokyo, cho, Chuo-ku 104-0044, Japan
}

and the rectum, CD may affect any part of the gut from the mouth to the perianal region, and up to $65 \%$ of CD patients may have the disease affecting the small intestine. The aetiology of IBD and factors, which provoke flare-ups are not understood well at present and this might be one factor for treatment failure and adverse side effects of currently available medications.

However, the human intestine is host to thousands of bacterial species, collectively referred to as the intestinal microbiota (2). While it is understood that the presence of this microbiota is essential for the human health, this 
relationship may become unbalanced, resulting in diseases like UC and CD [2,3]. Thus, both clinical and experimental evidence suggest that IBD fare-ups are triggered by a combined loss of the so-called intestinal barrier function and a dysregulated immune response to the intestinal microbiota [2-12]. Accordingly, in animal models of IBD, experimental colitis is reported not to occur under bacteria-free condition $[6,13,14]$. This seems paradoxical as the human intestinal bacteria are known to metabolize compounds that might be essential for human nutrition [15,16]. Additionally, probiotics, which change the composition of intestinal microbiota have shown efficacy in patients with IBD [3, 17-22], suggesting that among the vast species of bacteria which are found in the human intestine, there are both pro-inflammatory [23,24], as well as protective strains [17].

Although, the evidence for the role of intestinal microbiota in the flare-up as well as in the mitigation of intestinal inflammation is strong, there is also evidence that patients with IBD bear genetic susceptibility factors $[25,26]$, familial clustering and a high degree of IBD concordance [25-28]. Accordingly, there are families that have multiple relatives with $\mathrm{CD}$ or $\mathrm{UC}$, which provides evidence for genetic factors in the aetiology of IBD [27].

Given that intestinal microbiota in patients with IBD may bear features different from those in healthy individuals, characterization of these bacterial communities should be a major focus of the studies aimed at understanding of IBD aetiology. Based on this perception, gut bacterial community fingerprinting technique like the terminal restriction fragment polymorphism (T-RFLP) analysis can be applied to determine inter-individual differences in the gut microbiota [29-31]. Data from TRFLP investigations should provide clinically relevant information on the compositional differences of gut bacterial communities [30-32]. This article focuses on UC.

We thought that potentially, the application of $\mathrm{T}$ RFLP to the bacteria in faecal samples from patients with UC may provide a biomarker to trace UC in community based studies. Ideally, we hoped that such biomarker should be related to UC severity and the likelihood of a flare-up. Further, the application of TRFLP to interpret intestinal bacterial flora of UC patients and the patients' relatives, which potentially could reveal the development of UC within a consanguineous generation (related by blood) has not been attempted in the past. Likewise, cluster analysis applied in T-RFLP studies is a relative evaluation, yielding equivocal data [32]. In line with this assertion, cluster analyses in the present study also provided uncertain outcome. Instead, we applied quantitative Discriminant analyses of intestinal microbiota of UC patients and the patients' relatives. This approach provided clinically relevant data.

\section{Methods}

\section{Subjects}

Sixty-nine patients with UC, 41 female and 28 male, median age 46.5 years, range 13 to 79 years were included in this study. Additionally, an 80 relatives of the same patients, 40 female and 40 male, median age 45.2 years, range 2 to 78 years were included to broaden the scope of the study. The $69 \mathrm{UC}$ patients could be divided into group I $(n=23)$ with active $U C$, clinical activity index (CAI) $>3$ according to Lichtiger [32], and group II $(\mathrm{n}=46)$ with $\mathrm{UC}$ in quiescent phase $(\mathrm{CAI} \leq 3)$. Patients with quiescent UC could be divided further into 2 groups based on colonoscopic findings. Seventeen had mild inflammation in the large intestine (group IIa), and 29 had no obvious inflammation in the large intestine (group IIb). Likewise, the patients' relatives could be divided into two subgroups. Patients' akin (consanguineous relatives), like father, mother, a child, brother, or sister (group III, $\mathrm{n}=47$ ), and without blood relationship (non-consanguineous relatives), like husband, wife, father-in-law, mother-in-law (group IV, $\mathrm{n}=$ 33). Faecal samples were obtained from all subjects (Table 1) for the investigation of intestinal microbiota by applying the T-RFLP method (described below). All subjects were managed at the Division of Gastroenterology, St Luke's International Hospital, Tokyo. This investigation was registered with the UMIN, No. 000004123 http://www.umin.ac.jp/.

\section{Terminal restriction fragment length polymorphism (T-RFLP) procedures}

T-RFLP is a molecular biology technique developed for profiling bacterial communities based on the position of a restriction site closest to a labeled end of an amplified gene [29]. T-RFLP involves sequentially breaking down a mixture of polymerase chain reaction (PCR) amplified variants of a single gene by using one or more restriction enzymes and detecting the size of each individual terminal fragments with the aid of a DNA-sequencer. Essentially, T-RFLP can be applied to generate a fingerprint of an unknown bacterial community and trace it through a family or population. Faecal samples were suspended in a solution containing $100 \mathrm{mM}$ Tris- $\mathrm{HCl}$, pH 9.0, 40 mM Tris-EDTA, pH 8.0, and 4 M guanidine thiocyanate, and kept at $-20^{\circ} \mathrm{C}$ until DNA extraction. Aliquots of $0.8 \mathrm{ml}$ faecal suspensions were homogenized with zirconia beads in a $2.0 \mathrm{ml}$ screw cap tube by FastPrep FP120A Instrument (MP Biomedicals, Irvine, CA) and placed on ice. After centrifugation at 5000xg for $1 \mathrm{~min}$, the supernatant was transferred to the automated nucleic acid isolation system 12GC, and DNA extraction was done by using the Magtration MagaZorb DNA Common Kit 200 N (Precision System Science, Chiba, Japan). 
Table 1 Demographic variables of the included subjects

\begin{tabular}{llc}
\hline Subjects & Number of patient & Median age (yr) \\
\hline Group I: patients with active ulcerative colitis (UC) & 23 (8 male, 15 female) & 42.4 \\
Group Ila: patients with quiescent UC with mild intestinal inflammation & 17 (6 male, 11 female) & 42.3 \\
Group IIb: patients with quiescent UC & 29 (14 male, 15 female) & 52.3 \\
Group III: patients' consanguineous relatives & 47 (23 male, 24 female) & 40.1 \\
Group IV: patients' non-consanguineous relatives & 33 (17 male, 16 female) & 52.5 \\
\hline
\end{tabular}

\section{PCR amplification for T-RFLP analysis}

The 16S rDNA was amplified from human faecal bacterial DNA by using the fluorescently labeled $516 \mathrm{f}$ (5' -(6-FAM)-TGCCAGCAGCCGCGGTA-3'), and 1492r (5'-GGTTACCTTGTTACGACTT-3') primers. For this, the Hot-starTaq DNA polymerase by Gene Amp PCR system 9600 (Applied Biosystems) was used [33]. The amplification program was as follows: preheating at $95^{\circ} \mathrm{C}$ for $15 \mathrm{~min}, 30$ cycles of denaturation at $95^{\circ} \mathrm{C}$ for $30 \mathrm{~s}$, annealing at $50^{\circ} \mathrm{C}$ for $30 \mathrm{~s}$, extension at $72^{\circ} \mathrm{C}$ for $1 \mathrm{~min}$, and finally, a terminal extension at $72^{\circ} \mathrm{C}$ for $10 \mathrm{~min}$. The amplified DNA was pulyfied by a MultiScreen PCR96 Filter Plate (Millipore) and was verified by electrophoresis. The restriction enzymes were selected according to Nagashima et al. [34]. In brief, the PCR product was purified, and digested with BsII (New England BioLabs, Ipswich, USA). The resultant DNA fragments, viz., fluorecent labeled terminal restriction fragments (T-RFs), were analyzed by ABI PRISM 3130xl genetic analyzer, and its length and peak area were determined by using the genotype software GeneMapper (Applied Biosystems). The T-RFs were divided into 29 operational taxonomic units (OTUs). The OTUs were quantified as the percentage of individual OTU per total OTU areas, expressed as the percentage of area under the curve (\%AUC). The bacteria were predicted for each classification unit and the corresponding OTU was identified according to reference Human Faecal Microbiota (T-RFLP profiling, http:// www.tecsrg-lab.jp/).

\section{Ethical considerations}

Before contacting the study subjects, our protocol was reviewed and approved by the Screening Committee of St Luke's International Hospital (the study site). Likewise, informed consent was obtained from all patients and the patients' relatives by using the consent explanatory note document, which is recognized by the Screening Committee of St Luke's International Hospital. Subjects provided informed consent after being informed of the purpose of the study, and the nature of the procedures involved. In under age cases, consent from one of the patient's parents was sought. Additionally, adherence was made to the Principle of Good Clinical Practice and the Declaration of Helsinki at all times.

\section{Statistics}

When appropriate, numerical data are presented as the mean \pm SD values. The Discriminant Score (Ds) was calculated according to the following mathematical equation, $D s=d+\sum_{j=1}^{m}(d j \times \alpha j)$ where $\mathrm{m}=$ number of OTUs, $\alpha j=$ value of each OTU, $d j=$ Df value of each OTU, D = a constant and $j$ is a variable. The Discriminant analysis was performed by using the software SPSS (IBM Statistics 20.0). The t-statistic was applied to determine significance levels for the male and female ratio and the age difference between groups I to IV. Bacterial communities in faecal samples from BslI-digested T-RF patterns in groups I to IV were processed by One Way ANOVA.

\section{Results}

\section{Limitations of cluster analyses}

Hitherto, cluster analysis has routinely been applied to TRFLP data [29-32], shown in Figure 1. Therefore, in this study, we initially applied cluster analysis to our data. Although practical on data from two groups, but cluster analysis appeared to be complicated and the outcome unreliable when data from five groups were to be processed. It was thought that the difference of intestinal microbiota between patients with active UC (group I) and nonconsanguineous relatives (group IV) might be greater than between any other two groups. However, the cluster separation between groups I and IV was not apparent at all (Figure 2). We then thought that it might be realistic to apply the Discriminant analysis, which factors a mathematical model described in the statistics section.

\section{The outcomes of discriminant analysis}

In this study, the Discriminant analysis was applied to the data as quantitative approach based on the mathematical model mentioned above. The Canonical Discriminant Function Coefficient (Df) for each OTU value and a constant (see the equation in the statistics section) were calculated by using group I and group IV, in whom the intestinal microbiota difference was thought to be greatest among the four groups of subject in this study. Then the individual OTU values were multiplied by the aforementioned Df, and the total sum including a constant was termed the Discriminant Score (Ds) of an individual case. 


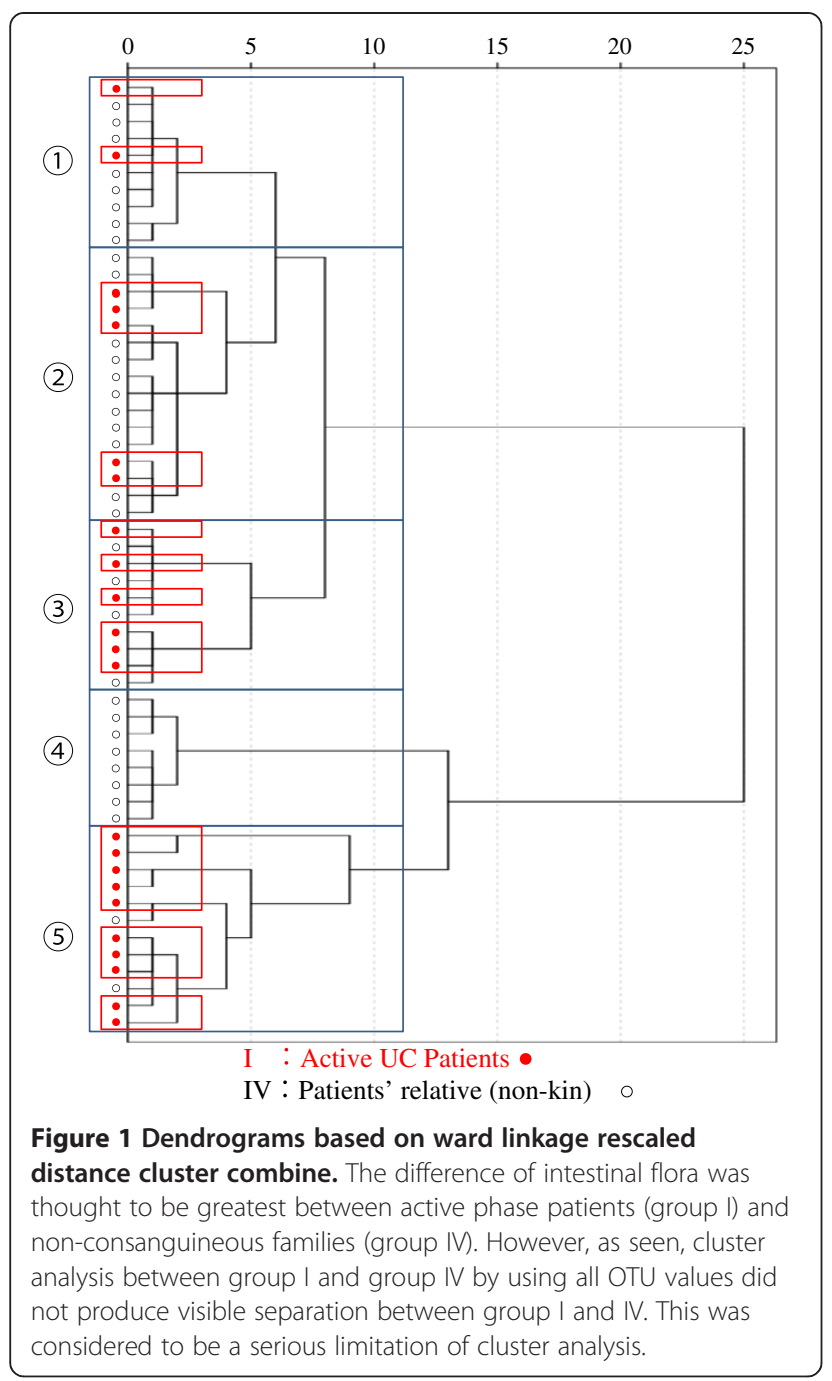

The Ds values for all cases were computed. The results were lucid and meaningful. The Ds values decreased in the following order: group I $>$ group IIa $>$ group IIb $>$ group III $>$ group IV. Significant differences were calculated by One Way ANOVA for group I vs group IV $(\mathrm{P}<$ $0.01)$, group I vs group IIb $(\mathrm{P}<0.05)$ group IIa vs group IV $(\mathrm{P}<0.01)$ and group III vs group IV $(\mathrm{P}<0.05)$. The outcomes are presented in Tables 2 and Figure 2.

Further, as certain strains of bacteria are thought to be associated with the development of UC, while others not so, this should show up in the OTU value in T-RFLP analysis. The analysis was set to factor this assumption, and the OTUs with 0 value $\geq 95 \%$ of all cases together with the OTUs of structure matrix value $\leq 0.01$ according to the Discriminant analysis were excluded, and the Discriminant analysis was done (Figure 3). Again the Ds value decreased in the order: group I $>$ group IIa $>$ group IIb $>$ group III $>$ group IV. The numerical values of Ds were: $1.04 \pm 1.15$ for group I, $0.53 \pm 1.40$ for group IIa, $0.32 \pm 1.00$ for group IIb, $0.09 \pm 0.84$ for group III and $-0.73 \pm 0.88$ for group IV.

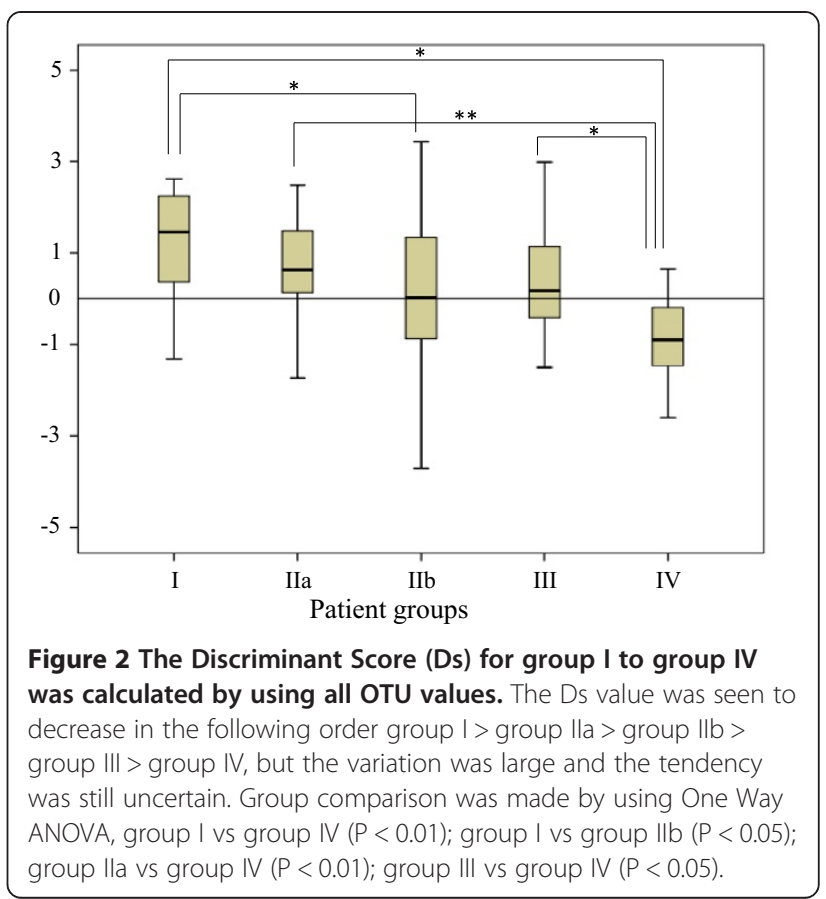

Significant difference was calculated for group I vs. group IV $(\mathrm{P}<0.01)$, group I vs. group IIb $(\mathrm{P}<0.05)$, group I vs. group III $(\mathrm{P}<0.01)$, group IIa vs. IV $(\mathrm{P}<0.01)$, and group IIb vs. group IV $(\mathrm{P}<0.01)$, group III vs. group IV $(\mathrm{P}<$ 0.01 ). The data are presented in Table 3 and Figure 3 . Clearly, the Ds value reflected UC disease activity (or lack of it) in the five groups of this study. Further, as the Ds value comes from the analyses on the intestinal microbiota and factors the OTU value, this parameter appears to be a clinically relevant biomarker of UC disease activity. Potentially, this means that analysis of bacterial flora by applying the mathematical model used in this study should become a routine practice. To our knowledge, this is the first report on the application of the Ds to the study of intestinal bacteria in faecal samples from UC patients' consanguineous and non-consanguineous relatives.

Table 2 The Discriminant Score (Ds) from all OTU values (see Figure 2)

\begin{tabular}{lc}
\hline Subjects & $\begin{array}{c}\text { Ds value } \\
\text { (mean } \pm \text { SD) }\end{array}$ \\
\hline Group I: Patients with active ulcerative colitis (UC) & $1.24 \pm 1.17$ \\
Group Ila: Patients with quiescent & $0.78 \pm 1.76$ \\
UC with mild intestinal inflammation & \\
Group IIb: Patients with quiescent & $-0.10 \pm 2.43$ \\
UC (without inflammation) & \\
Group III: Patients' consanguineous relatives & $0.25 \pm 1.39$ \\
Group IV: Patients' non- consanguineous relatives & $-0.87 \pm 0.87$ \\
\hline
\end{tabular}




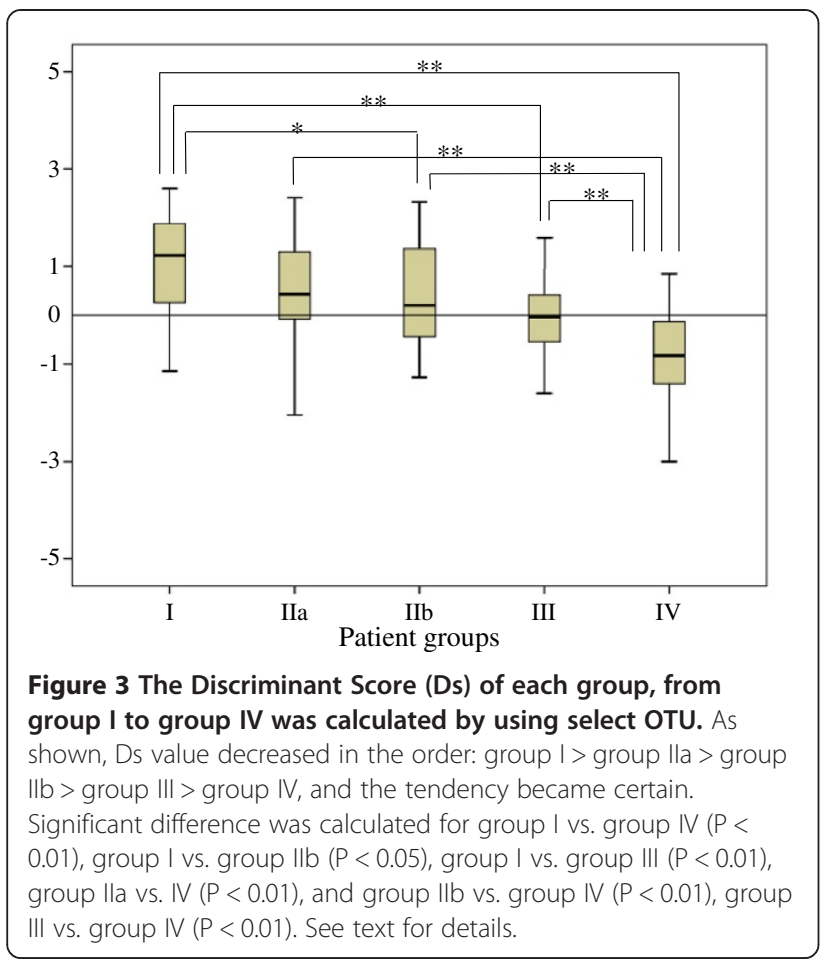

\section{Discussion}

The knowledge that the intestinal microbiota in patients with UC is a major factor in the aetiology of this condition is supported by animal models of colitis, reporting that the development of UC-like colitis did not occur under bacterial free conditions $[14,15]$, but in the same setting, colitis occurred following introduction of gut bacteria from a UC patient [14]. In contrast, faecal bacteria from healthy donors are expected to have therapeutic effect in patients with IBD [35]. With this background in mind, we became interested to evaluate a biomarker based on the gut microbiota, being closely related to UC activity and potentially could indicate a UC relapse. The findings of this study might be summarized as follows. Our study subjects were divided into five groups and included patients with $\mathrm{UC}$ in active phase, in quiescent phase (with and without mild mucosal inflammation), UC patients' consanguineous and non-consanguineous relatives. The latter two groups served as non-IBD controls with and without having blood relationship with the UC groups. In processing of the

Table 3 The Discriminant Score (Ds) from selected OTUs related to the data presented in Figure 3

\begin{tabular}{lc}
\hline Subjects & Ds value (mean \pm SD) \\
\hline Group I & $1.09 \pm 1.13$ \\
Group IIa & $0.69 \pm 1.59$ \\
Group IIb & $0.27 \pm 1.05$ \\
Group III & $0.03 \pm 0.81$ \\
Group IV & $-0.76 \pm 0.90$ \\
\hline
\end{tabular}

T-RFLP data, cluster analysis [34,36,37], which hitherto studies have frequently applied did not seem to work when applied to five groups in this study. Then we thought that it might be logical to apply the Discriminant analysis, together with a mathematical model (shown in the statistics section). Among the five groups, the Ds value was positive and greatest in group I with active UC, smallest and negative in group IV who had neither any evidence of IBD nor blood relationship with the UC patients. This was quite interesting as only in this group, the magnitude of the Ds value was negative. Therefore, the interpretation of the Ds values could mean that patients with UC and their non-IBD relatives share intestinal microbiota, which may not be present in non-IBD/non-consanguineous relatives. As the Ds value comes from the analyses on the intestinal microbiota, and factors the OTU value, the Ds appears to be a clinically relevant biomarker of UC disease activity. Potentially, this means that analysis of bacterial flora by applying the mathematical model used in this study should become a routine practice. Additionally, it should be appropriate to mention here that current treatment regimens for UC, which include corticosteroids, thiopurines (6-mercaptopurine, and azathioprine) or biologics such as infliximab that block the activity of the inflammatory cytokine tumour necrosis factor (TNF)- $\alpha$ have shown efficacy in this clinical setting, but are without effect on the underlying basis of the disease like dysbacteriosis.

Progress in understanding factors, which are closely associated with the expression and the exacerbation of UC should lead to better management of this disorder. Intestinal bacterial flora fingerprinting techniques like TRFLP analysis [29,30], potentially offer a rapid view of interindividual differences in gut bacterial flora, and whether or not such differences define UC profile. When comparing the T-RFLP data obtained from different populations, variation can be found in the number and size of peaks and can be evaluated by selecting features like richness and evenness. The technique is designed to provide quantitative information on the compositional differences of intestinal bacteria with the potential to serve as a biomarker in population based studies. However, to be relevant as a biomarker, T-RFLP data need to be highly reproducible and reflect the composition of intestinal microbiota. In addition to the limitations of cluster analysis already mentioned, methodological approaches like sampling technique and DNA extraction, have the potential to influence the T-RFLP fingerprint of microbial communities [38]. Therefore, obtaining microbial genomic DNA that accurately represents the gut microbial community is essential $[30,34]$. When extracting genomic DNA from a complex matrix such as faeces, not only is extraction efficiency of genomic DNA from a wide variety of bacteria an essential consideration but removal of contaminants that co-elute with the DNA may interfere with the subsequent 
molecular analyses is necessary as well. With these limitations in mind, we applied the DNA extraction method described by Nagashima et al., which provides reproducible data [34].

In this study, our major endeavour was to evaluate a simple and reliable model for thorough investigation of the role of intestinal bacterial in the aetiology of UC $[39,40]$. All specimens needed could be extracted from faecal samples. However, given the fact that there are strain of bacteria, which are part of the aetiology of IBD, while other strains are protective [35,41], a comparison of the Ds values from the UC patients and non-IBD relatives in this study did not lead to the identification of a specific sequence or group of sequences exclusively harbored by UC patients. Therefore, it was not possible to relate certain bacterial species to the presence or absence of UC. The most obvious difference in the mucosa-associated flora from the UC and non-IBD patients was the absolute value of Ds. The Ds should be appropriate for assessing the clinical state and treatment policy in patients with UC. It was thought that in patients with a definitive diagnosis of UC, a low Ds value could indicate stable remission and vice versa. We also noticed that a high OTU value was related to the severity of active UC.

\section{Conclusions}

Intestinal microbiota fingerprinting techniques, like the TRFLP analysis, potentially offer a rapid overview of interindividual differences in gut bacterial flora. Analyses of intestinal microflora of UC patients and their relatives based on T-RFLP, and the determination of the Ds values by using the selected OTUs indicated that the risk becomes high as the Ds value increases. This method should be valuable as a quantitative assessment of patient's intestinal microflora. To our knowledge, this is the first report on the application of the Ds value to the study of intestinal bacteria in faecal samples from UC patients, patients' consanguineous and non-consanguineous relatives. Future studies should look for bacterial species, which are associated with the aetiology of IBD or otherwise are protective. Likewise, understanding the mechanisms by which intestinal mirobiota contribute to the exacerbation of IBD should reflect significant progress.

\footnotetext{
Abbreviations

ANOVA: Analysis of variance; CAl: Clinical activity index; CD: Crohn's disease; Df: Discriminant function coefficient; DNA: Deoxyribonucleic acid; Ds: Discriminant score; IBD: Inflammatory bowel disease; OTU: Operationaltaxonomic-unit; PCR: Polymerase chain reaction; TNF: Tumour necrosis factor; TRF: Terminal restriction fragments; T-RFLP: Terminal restriction fragment length polymorphism.
}

\section{Competing interests}

The authors declare that they have no competing interest.

\section{Authors' contributions}

Katsuyuki Fukuda, MD, PhD, was fully involved in the conception, study design, patient management, acquisition and interpretation of the data, statistics, drafting, and preparation of the final manuscript version. Yoshiyuki Fujita, MD contributed to collection of test samples, interpretation of the data and critical review of the final manuscript version. All laboratory assays were commissioned by TechnoSuruga Laboratory Co., Ltd., Shizuoka, Japan and were paid for by the authors' institute. Both authors read and approved the final version of the manuscript.

\section{Acknowledgement}

No external fund was used in carrying out this investigation.

Received: 11 September 2013 Accepted: 6 March 2014

Published: 19 March 2014

\section{References}

1. Podolsky DK: Inflammatory bowel disease. N Engl J Med 2002, 347:417-429.

2. Neish AS: Microbes in gastrointestinal health and disease.

Gastroenterology 2009, 136:65-80.

3. Uronis JM, Arthur JC, Temitope KT: Gut microbial diversity is reduced by the probiotic VSL\#3 and correlates with decreased TNBS-induced colitis. Inflamm Bowel Dis 2011, 17:289-297.

4. Xavier R, Podolsky DK: Unraveling the pathogenesis of inflammatory bowel disease. Nature 2007, 448:427-434.

5. Strober W, Fuss I, Mannon P: The fundamental basis of inflammatory bowel disease. J Clin Invest 2007, 117:514-521.

6. Sartor RB: Microbial factors in the pathogenesis of Crohn's disease, ulcerative colitis and experimental intestinal inflammation. In Inflammatory Bowel Disease. 5th edition. Edited by Kirsner JB. Baltimore: Williams \& Wilkins; 1999:153-158.

7. Bonen DK, Cho JH: The genetics of inflammatory bowel disease. Gastroenterology 2003, 124:521-536.

8. Hu S, Wang Y, Lichtenstein L, Tao Y, Musch MW, Jabri B, Antonopoulos D, Claud EC, Chang EB: Regional differences in colonic mucosa-associated microbiota determine the physiological expression of host heat shock proteins. Am J Physiol Gastrointest Liver Physiol 2010, 299:G1266-G1275.

9. Campieri M, Gionchetti P: Bacteria as the cause of ulcerative colitis. Gut 2001, 48:132-135.

10. Krishnan A, Korzenik JR: Inflammatory bowel disease and environmental influences. Gastroenterol Clin North Am 2002, 31:21-39.

11. Sartor RB: Microbial influences in inflammatory bowel disease: role in pathogenesis and clinical implications. In Kirsner's Inflammatory Bowel Diseases. Philadelphia: WB Saunders; 2004:138-162.

12. Swidsinski A, Ladhoff A, Pernthaler A, Swidsinski S, Loening-Baucke V, Ortner M, Weber J, Hoffmann U, Schreiber S, Dietel M, Lochs H: Mucosal flora in inflammatory bowel disease. Gastroenterology 2002, 122:44-54.

13. Baumgar DC, Carding SR: Inflammatory bowel disease: cause and immunobiology. Lancet 2007, 369:1627-1640.

14. Ohkusa T, Okayasu I, Ogihara T, Morita K, Ogawa M, Sato N: Induction of experimental ulcerative colitis by fusobacterium varium isolated from colonic mucosa of patients with ulcerative colitis. Gut 2003, 52:79-83.

15. Buchler G, Wos-Oxley ML, Smoczek A, Zschemisch NH, Neumann D, Pieper $\mathrm{DH}$, Hedrich HJ, Bleich A: Strain-specific colitis susceptibility in IL10deficient mice depends on complex gut microbiota-host interactions. Inflamm Bowel Dis 2012, 18:943-954.

16. Cummings JH, Macfarlane GT: Colonic microflora: nutrition and health Nutrition 1997, 13:476-478.

17. Sokol H, Seksik P, Furet JP, Firmesse O, Nion-Larmurier I, Beaugerie L, Cosnes Corthier G, Marteau P, Doré J: Low counts of Faecalibacterium prausnitzii in colitis microbiota. Inflamm Bowel Dis 2009, 15:1183-1189.

18. Sartor RB: Therapeutic manipulation of the enteric microflora in inflammatory bowel diseases: antibiotics, probiotics, and prebiotics. Gastroenterology 2004, 126:1620-1633.

19. Kanauchi O, Mitsuyama K, Araki Y, Andoh A: Modification of intestinal flora in the treatment of inflammatory bowel disease. Curr Pharm Des 2003, 9:333-346

20. Tsuda Y, Yoshimatsu Y, Aoki H, Nakamura K, Irie M, Fukuda K, Hosoe N, Takada N, Shirai K, Suzuki Y: Clinical effectiveness of probiotics therapy (BIO-THREE) in patients with ulcerative colitis refractory to conventional therapy. Scand J Gastroenterol 2007, 42:1306-1311. 
21. Furrie E, Macfarians S, Kennedy A, Cummings JH, Walsh SV, O'Neil DA, Macfarlane GT: Synbiotic therapy (Bifidobacterium longum/Synergy 1) initiates resolution of inflammation in patients with active ulcerative colitis: a randomized controlled pilot trial. Gut 2005, 54:242-249.

22. Sartor RB: Probiotic therapy of intestinal inflammation and infections. Curr Opin Gastroenterol 2005, 21:44-50.

23. Nishikawa J, Kudo T, Sakata S, Benno Y, Sugiyama T: Diversity of mucosaassociated microbiota in active and inactive ulcerative colitis. Scand J Gastroenterol 2009, 44:180-186.

24. Joossens M, Huys G, Cnockaert M, De Preter V, Verbeke K, Rutgeerts $P$, Vandamme $P$, Vermeire S: Dysbiosis of the faecal microbiota in patients with Crohn's disease and their unaffected relatives. Gut 2011, 60:631-637.

25. Brant SR: (Editorial). Update on the heritability of inflammatory bowel disease: the importance of twin studies. Inflamm Bowel Dis 2011, 17:1-5.

26. Barrett JC, Hansoul S, Nicolae DL, Cho JH, Duerr RH, Rioux JD, Brant SR, Silverberg MS, Taylor KD, Barmada MM, Bitton A, Dassopoulos T, Datta LW, Green T, Griffiths AM, Kistner EO, Murtha MT, Regueiro MD, Rotter II, Schumm LP, Steinhart AH, Targan SR, Xavier RJ, Genetics Consortium NIDDKIBD, Libioulle C, Sandor C, Lathrop M, Belaiche J, Dewit O, Gut I, et al: Genome-wide association defines more than 30 distinct susceptibility loci for Crohn's disease. Nat Genet 2008, 40:955-962.

27. Orholm M, Munkholm P, Langholz E, Nielsen $\mathrm{OH}$, Sørensen TI, Binder V: Familial occurrence of inflammatory bowel disease. N Engl J Med 1991 324:84-88.

28. McGovern DP, Gardet A, Torkvist L, Goyette P, Essers J, Taylor KD, Neale BM, Ong RT, Lagacé C, Li C, Green T, Stevens CR, Beauchamp C, Fleshner PR, Carlson M, D'Amato M, Halfvarson J, Hibberd ML, Lördal M, Padyukov L, Andriulli A, Colombo E, Latiano A, Palmieri O, Bernard EJ, Deslandres C, Hommes DW, de Jong DJ, Stokkers PC, Weersma RK, et al: Genome-wide association multiple ulcerative colitis susceptibility loci. Nat Genet 2010, 42:332-337.

29. Liu WT, Marsh TL, Cheng H, Forney L: Characterization of microbial diversity by determining terminal restriction fragment length polymorphisms of genes encoding 16S rRNA. Appl Environ Microbiol 1997, 63:4516-4522.

30. Li F, Hullara M, Lampe J: Optimization of terminal restriction fragment polymorphism (TRFLP) analysis of human gut microbiota. J Microbiol Methods 2007, 68:303-311.

31. Andoh A, Sakata S, Koizumi Y, Mitsuyama K, Fujiyama Y, Benno Y: Terminal restriction fragment length polymorphism analysis of the diversity of faecal microbiota in patients with ulcerative colitis. Inflamm Bowel Dis 2007, 13:955-962.

32. Sakamoto M, Hayashi $H$, Benno $Y$ : Terminal restriction fragment length polymorphism analysis for human faecal microbiota and its application for analysis of complex bifidobacterial communities. Microbiol Immunol 2003, 47:133-142.

33. Lichtiger $\mathrm{S}$, Present $\mathrm{DH}$, Kornbluth $\mathrm{A}$ : Cyclosporine in severe ulcerative colitis refractory to steroid therapy. N Engl J Med 1994, 330:1841-1845.

34. Nagashima $K$, Hisada T, Sato M, Mochizuki J: Application of new primer-enzyme combinations to terminal restriction fragment length polymorphism profiling of bacteria populations in human feces. Appl Environ Microbiol 2003, 69:1251-1262.

35. Anderson JL, Edney RJ, Whelan K: Systematic review: faecal microbiota transplantation in the management of inflammatory bowel disease. Aliment Pharmacol Ther 2012, 36:503-516.

36. Matsuda H, Fujiyama Y, Andoh A, Ushijima T, Kajinami T, Bamba T: Characterization antibody response against rectal mucosa-associated bacterial flora in patients with ulcerative colitis. $J$ Gastroenterol Hepatol 2000, 15:61-68.

37. Lucke K, Miehlke S, Jacobs E, Schuppler M: Prevalence of bacteroides and provetella spp. in ulcerative colitis. J Med Microbio/ 2006, 55:617-624

38. Burgmann $\mathrm{H}$, Pesaro M, Widmer F, Zeyer J: A strategy for optimizing quality and quantity of DNA extracted from soil. J Microbiol Methods 2001, 45:7-20.

39. Marteau P, Lepage P, Mangin I, Suau A, Doré J, Pochart P, Seksik P: Review Article: gut flora and inflammatory bowel disease. Aliment Pharmacol Ther 2004, 20(supple 4):18-23.
40. Lepage $P$, Seksik $P$, Sutren $M$, de la Cochetière $M F$, Jian $R$, Marteau $P$, Doré J: Biodiversity of the mucosa-associated microbiota is stable along the distal digestive tract in healthy individuals and patients with IBD. Inflamm Bowel Dis 2005, 11:473-480.

41. Kojima A, Nakano K, Wada K, Takahashi H, Katayama K, Yoneda M, Higurashi T, Nomura R, Hokamura K, Muranaka Y, Matsuhashi N, Umemura K, Kamisaki Y, Nakajima A, Ooshima T: Infection of specific of Streptococcus mutans, oral bacteria, confers a risk of ulcerative colitis. Sci Rep 2012, 2(332):1-11.

doi:10.1186/1471-230X-14-49

Cite this article as: Fukuda and Fujita: Determination of the discriminant score of intestinal microbiota as a biomarker of disease activity in patients with ulcerative colitis. BMC Gastroenterology 2014 14:49.

\section{Submit your next manuscript to BioMed Central and take full advantage of:}

- Convenient online submission

- Thorough peer review

- No space constraints or color figure charges

- Immediate publication on acceptance

- Inclusion in PubMed, CAS, Scopus and Google Scholar

- Research which is freely available for redistribution

Submit your manuscript at www.biomedcentral.com/submit
C Biomed Central 